\title{
Mainstreaming and the ESL/D Program: the Highgate Public School Experience
}

\author{
Rashida Mirza, Linda Brown, Toba Balaban
}

This article begins with a statement of the philosophy of the Principal of Highgate Public School regarding mainstreaming ESL/D children. It goes on to describe the kind of population served by Highgate, the assessment and the placement of the ESL/D child.

The ESL/D Level I program is explained using a description of activities and of the initial stages of integration into the regular classroom. The Level II and Level III programs are then discussed. Ways to adapt the regular class to the needs of the second language learner, and alternate ways of grouping to enhance opportunities for success are highlighted. Finally, an example of a unit used as a cooperative learning experience for regular students working with ESL/D students is given.

Highgate Public School within Ontario's York region to the north of Toronto has a student body comprised mainly of children for whom English is a second language. With 720 students enrolled, the school currently employs the equivalent of $2.5 \mathrm{ESL} / \mathrm{D}$ teachers who work together as a team.

Principal Norm Barnard describes the philosophy which underlies the school's approach to ESL/D instruction: "In order that the ESL/D children can feel as much a part of the regular program as possible, and so that teaching is relevant to their classroom experiences, it is important that the ESL/D children receive their instruction in the regular classroom."

\section{THE PROGRAM}

The first three weeks in September are devoted to registering and testing ESL/D students in order to divide them into Levels I, II or III, and to assign them to one of the three ESL teachers.

\section{Level I}

If there are Level I students, they are further divided into primary and junior groups. Primaries and juniors are withdrawn from regular class for part of the day, but only until they show evidence of being able to survive in a regular classroom setting. The primaries are with- 
drawn from 9:00 a.m. to recess and the juniors from recess to noon. Both groups go to an ESL classroom which the three ESL/D teachers share. The withdrawal teacher then spends the afternoon visiting these same Level I students in their regular classrooms. Her role there is to help them to follow the program of the regular classroom teacher as best as they can. Sometimes this involves adapting classroom work to a level suitable for a Level I student.

In the afternoon session, for example, during a regular classroom Grade five group project on "Mediaeval times", the ESL/D students did the illustrations for the text being written by the other students. The ESL/D teacher worked on vocabulary input (oral and written) which the ESL/D students would need to learn for presentation to the others at project evaluation time.

Sometimes the Level I teacher may work on a project in the morning ESL/D withdrawal sessions which children may present to their regular classes. In one such instance, students first visited a nearby bush area to study its fauna and flora. Following this, students used their withdrawal classes to create a "found object" sculpture by sticking ferns, tree bark, burrs, and acorns into styrofoam slabs. Junior ESL/D students then went back to their regular classrooms and gave a mini-lesson on their trip to the bush, using whatever English they had learned during a week or so of study with their ESL/D teacher. As they fielded their classmates' questions, they became the experts and appeared to lose any feelings of self-consciousness about using the language.

Every second Friday, each ESL/D student may invite two friends from class to come to the ESL/D room for 40 minutes and share in the work students are doing there. ESL/D students read their journal entries, show off any science or art projects they are involved in, play learning games or paint a cooperative picture. Regular classroom students clamour to be chosen. It makes the ESL/D classroom and the regular classroom more closely related to each other.

\section{Levels II and III}

In Levels II and III, the mainstreaming model can be followed more completely. Students at these levels are not withdrawn, except in special circumstances where noise control or distractability is a problem. The ESL/D teacher who works with students in a mainstreamed classroom assumes somewhat different responsibilities from those of an ESL/D withdrawal teacher.

In a mainstreamed program, the development of both receptive and expressive language skills within the regular classroom environment and the ESL/D program related to the classroom become even more important than in Level I. The objectives of both the regular classroom 
teachers and their ESL/D counterparts working at Levels II and III fall under three general headings:

1. To maximize student participation in the regular classroom program;

2. To allow students to experience success at their current levels;

3. To build students' self-esteem.

To allow ESL/D students to participate successfully in regular classroom activities, ESL/D instructors and regular classroom teachers often have to work together to modify programs. During implementation of the mainstreamed model, the ESL/D instructor still continues with students in need; at the same time, the instructor is called on more and more to act as a resource person.

One way in which the ESL/D teacher can assist is by making concrete suggestions to the regular classroom teacher for modifying a program. These include:

1. Consider the student's level of cognitive development when planning a program.

2. Emphasize process rather than product. Remember that receptive skills develop more quickly than expressive language skills, so don't be overly concerned with product.

3. Be flexible. Be willing to adapt or replace inappropriate activities to suit the skill level of the student. (For example, let new students write in their native language.)

4. Avoid overuse textbooks. Students who cannot read close to grade level are capable of understanding the concepts and skills being taught if they are presented using appropriate materials.

5. Provide a wide range of materials at different levels to support your units of study. Use lots of concrete, hands-on materials, a variety of audiovisual aids, and suitable books. When necessary, try primary literature for junior students as long as the material is not babyish. Try patterned and predictable books, wordless books, and low vocabulary, high interest books.

6. Provide a broad range of language activities including drama, puppetry and screen arts activities to promote oral and written language development.

7. Present themes in an activity-centred approach.

8. Simplify language used in written instructions and on task cards used in activity centres.

9. Emphasize and build on student strengths. Help students to "shine" wherever possible in both academic and non-academic subjects, as well as in social situations.

10. Integrate Canadian culture into your program (for example, holidays, cooking). Holidays such as Hallowe'en can be very confusing to children from some countries. 
11. Integrate multicultural content into your curriculum in the form of holidays, food, music and dance, for example. Show both similarities and differences in a positive light. Help students develop a cultural awareness and sensitivity towards others.

12. Encourage participation in all aspects of the school program, including extra-curricular activities.

13. Be patient. Some progress is difficult on a day-to-day basis. Often students require time to consolidate what they have learned. According to Cummins (1984), immigrant children require five to seven years (on the average) in the host country to approach native norms in second language conceptual and literacy skills.

Another way in which the ESL/D teacher can assist the regular classroom teacher is by suggesting different ways of grouping students. A good general rule to follow for any approach is to avoid always grouping according to ability. Groupings should not be left to chance, either. It is often wise to assign a buddy to new students to help translate, point out facilities, explain routines or work, or assist with work in the regular program. Buddies may be advanced ESL/D students or Canadian-born students. ESL/D students are able to appreciate the difficulties of adjustment to a new language or culture. Use of Canadian-born buddies, however, may facilitate understanding and appreciation of cultural differences.

Each type of grouping has its own advantages:

- small groups may be necessary for students who find it difficult to speak in front of others;

- mixed racial/ethnic groups can help a student feel more comfortable with children of different racial and ethnic backgrounds;

- mixed ability groups allow peer assistance to occur naturally; new students are provided with good behaviour models of behaviour and work habits; the ESL/D student avoids always being in the "low" group;

- cooperative learning allows students to work on activities in small groups; recognition is based on the group's performance. Students may be assigned a different portion of the task in their group. Task completion is contingent upon mutual cooperation. Cooperative learning has been found to increase academic achievement, particularly for minority group members. This improvement is most dramatic at the oral level since each student becomes a "teacher". It also increases group cohesiveness and inter-racial mixing and comfort levels. Lastly, it has a positive effect on student self-concept, partly because it is non-competitive. 


\section{Language-Experience Approach}

In Highgate Public School, all of the teachers run "language-experience" programs. According to this model, classrooms are run on a learning centre approach. At these centres, children have an opportunity to do hands-on activities around a central theme. All subject areas are integrated into the theme. Oral and written language is generated through these experiences at the centres. To use this approach is not difficult, as the ESL/D teacher can always find a corner in a regular classroom to work with two or three students. When the regular children are working on process writing, the ESL/D teacher takes her students during this time and helps them with their particular needs in the language development skills. Often there are a few regular classroom students who also need the mini-lesson being offered, arid so they are included with the ESL/D students.

Generally, the ESL/D teacher can use a particular theme being studied in a regular classroom program. By developing a mini-unit around the theme, one can make it more suitable to the particular needs of the ESL/D children. In one such instance, in a Grade two classroom where the four ESL/D students needed a lot of oral practice, the poem "Over in the Meadow" was selected from one of the classroom readers being used by the teacher. The classroom study of "animals" was followed using the poem as a base. The ESL/D group learned the poem as a song and then learned to read it using the song sheets. Over a period of three weeks, skill work on rhyming words, verb tense and agreement, prepositions, action verbs, and more was done using the poem as a starting point.

During activity time, when the regular classroom students were working in groups, the ESL/D children worked in the story area. At this time, one or two non-ESL/D students would often join in the flashcard games or the singing. As a finale, the ESL/D children made a book illustrating the song and then presented it to the whole class. Next, the class was given a cloze passage of the song and the ESL/D children who had done the cloze prior to this became the "teachers" and marked the class work. The regular classroom teacher followed this activity with a request to her whole class to make a Hallowe'en book which began, "Over in the haunted house . . .."

As this theme sample shows, cooperation between regular classroom and ESL/D teachers enhances learning possibilities, and regular classroom teachers are quick to find other ways to use the services of ESL/ $D$ resource persons in the classroom:

\section{A Theme Unit Approach}

Another way an ESL/D teacher may support the regular classroom 
teacher is by doing a unit with the whole class. This allows her to show how the ESL/D students too can participate. The following illustrates this support technique.

One of the Highgate ESL/D teachers did a cooperative learning unit with a Grade six class over a period of several weeks. (For an outline of the unit, see Appendix 1.) Children were broken into groups of six. Each group worked with objects which make sounds (such as glass jars) until they had made a pattern of sound such as tap-tap-pause, tap, tap, pause. They wrote a story to depict the sound patterns. The story was then made into a mural by each group. Next, they created a mime play depicting the mural and used the sound pattern as background music. All the groups presented to the class in turn, and later fielded questions about the process of creating music and mime that they had gone through. The ESL/D teacher was a resource person, showing the classroom teacher and the students how the ESL/D children could be included, what they were capable of, and how the regular students could help them learn. Students discovered that their ESL/D friends had unexpected strengths which had not been detected because of assumed barriers of language.

\section{CONCLUSION}

In Highgate Public School, ESL/D teachers who support regular classroom teachers through activities such as the unit work described above are eagerly sought after throughout the school. Regular teachers understand that the ESL/D resource persons are there to support, not interrupt or judge. Students within regular classes also welcome the ESL/D component. It is not uncommon for the ESL/D staff to hear requests from non-ESL/D children to join into ESL/D programs. All the Highgate students, in fact, have come to regard the ESL/D programs, withdrawal or integrated, as an enriching and sometimes exciting experience. They feel the programs have a valuable place within the life of the school.

Principal Barnard's words summarize well the spirit of the Highgate experience:

In order that the ESL/D children can feel as much a part of the regular program as possible, it is important that children receive their instruction in the regular classroom ... to this end the teachers of Level II and III students work as a team with classroom teachers. Their main objective is to act as support for children as they go about their daily activities. The ESL/D teachers have become skilled in recognizing the needs of the children in these settings and programming to meet these needs. Level I students 
are still withdrawn, but only until they show evidence of being able to survive in the regular classroom setting. None of the above instruction prevents a child who really needs individual attention or withdrawal because of severe distractability, etc., from being withdrawn for part of the day. It must be stressed, however, that our goal remains integrated instruction for all ESL/D students.

\section{REFERENCES}

Basman, S., Bateman, J. \& Doyle, S. (1977). ESL/D reception language centre for the Bathurst family. (School Information booklet available from the Board of Education for the City of North York, 5050 Yonge Street, North York M2N 5N8.)

Cummins, J. (1984). Bilingualism and special education: issues in assessment and pedagogy. Clevedon, England: Multilingual Matters.

Kehoe, J. (1983). Enhancing the Multicultural Climate of the School. The History and Social Science Teacher. 19(2), 65-73.

Mock, K.R. (1983). The Successful Multicultural Teacher. The History and Social Science Teacher. 19(2), 87-97.

Sharan, S. (1980). Co-operative Learning in Small Groups: Recent Methods and Effects on Achievement, Attitudes and Racial Relations. Review of Educational Research Journal. 50(2), 240-271.

Slavin, R.E. (1980). Co-operative Learning. Review of Educational Research Journal. 50(2), 315-342.

Ziegler, S. (no date) Using Co-Operative Learning Teams to Increase CrossEthnic Friendship in Grade Six Classrooms in Toronto, Child in the City Programme. Unpublished manuscript. University of Toronto.

\section{THE AUTHORS}

Rashida Mirza is an ESL/D lead teacher at Highgate Public School, York Region Board of Education. She is also one of the subject leaders of Heritage Language Programs with the Board of Education for the City of North York.

Linda Brown is presently teaching ESL/D at Highgate School in York Region. She previously taught four years in Arctic Canada, and six years at an Inner City School in Toronto.

Toba Balaban is an elementary level teacher who has taught in the Toronto area for ten years. She is currently teaching ESL/D in the York Region Board of Education. 
APPENDIX

Cooperative Learning Unit: Beats and Rhythm

\section{OBJECTIVE SKILLS}

Students will be able to:

1. Work cooper- Cooperation atively on a

project in

groups

2. Listen to different sounds and develop a pattern to record on a cassette tape

3. Interpret sounds using their imagination, and come up with a visual display

4. Present their work orally in class

Presentation
skills:
(Speaking)

Use skills to
make patterns
with beats \&
rhythms

Using their. imagination (Speaking)

5. Write a story about their visual display
ACTIVITIES RESOURCES

SUBJECT
Music by Ustad Music

Allah Rakha

(Classical

Indian)

ments.
Listen to dif- Examples: Listening
ferent sounds Sand in a jar, 'Language and make a Nails in a Arts) pattern using paper bag beats and rhythm. Collect objects that make interest- ing sounds.

Visual Arts
Make a mural Students' of the interpre- imagination tation of their music created by different sounds.
Each member Past experi- Drama of the group ence of the will take part members in the presen- tation.
Discuss with Students' Writing group members imagination; and come up their experience with an inter- and their esting story creative writ- about the ting skills mural.
6. Evaluation by Critical think- After each the group: To ing and con- think critically structive presentation Students' Speaking for improve- ment and suggestions; and class will knowledge and Listening their experi- Analyzing give positive ences Helping constructive giving positive feedback and also discuss criticism how they would improve on the idea.

